УДК 536.24+662.995

\title{
ПЕРСПЕКТИВЫ ВЫРАЩИВАНИЯ И ИСПОЛЬЗОВАНИЯ ЭНЕРГЕТИЧЕСКИХ КУЛЬТУР В УКРАИНЕ. ЧАСТЬ 2
}

Гелетуха Г.Г., канд. техн. наук, Железная Т.А., канд. техн. наук, Трибой А.В.

Институт технической теплофизики НАН Украины, ул. Желябова, 2а, Киев, 03680, Украина

Розглянуто паливні характеристики енергетичних культур. Проаналізовано недоліки енергокультур як палива, запропоновано шляхи пом'якшення їх негативного впливу. Розглянуто сучасний стан та перспективи розвитку даного сектору в Україні. Запропоновано концепцію вирощування енергетичних культур в Україні.

Бібл. 13, рис. 5.
Рассмотрены топливные характеристики энергетических культур. Проанализированы недостатки энергокультур как топлива, предложены пути смягчения их негативного влияния. Рассмотрено современное состояние и перспективы развития данного сектора в Украине. Предложена концепция выращивания энергетических культур в suggested.

Ключевые слова: энергетические культуры, энергетические плантации, биомасса, биотопливо, биоэнергетика.

\section{Топливные характеристики энергетиче- ских культур \\ Энергетические культуры используются для} получения твердых, жидких и газообразных биотоплив. В данной статье рассматриваются культуры, предназначенные для производства твердых биотоплив - щепы, гранул, брикетов. Топливные характеристики нескольких таких культур представлены в таблице 1. Для сравнения в таблицу также включены данные для соломы зерновых культур и щепы лесной древесины.

Анализ данных таблицы показывает, что характеристики ивы и тополя в целом близки к показателям древесной щепы. Основное отличие - бо́льшее содержание азота, что, по-видимому, связано с применением удобрений при выращивании этих культур. Мискантус характеризуется повышенной зольностью, примерно такой, как у соломы. Все рассмотренные энергокультуры имеют достаточно высокую температуру плавления золы, что выгодно отличает их от соломы.

Ниже кратко представлены результаты нескольких работ, посвященных изучению топливных характеристик ряда энергетических культур.
В работе [1] на лабораторном оборудовании выполнено детальное исследование топливных свойств 6 генотипов биомассы ивы с точки зрения возможности их совместного сжигания с углем на электростанциях Великобритании. Отмечено, что положительным свойством ивы как топлива, является сравнительно небольшое содержание золы и азота. Применение удобрений при выращивании культуры должно быть оптимальным, так как оно оказывает влияние на элементный состав биомассы. Например, совместное использование азотных и калийных удобрений приводит к увеличению содержания углерода, что, в свою очередь, положительно влияет на калорийность биомассы. С другой стороны, использование этих же удобрений влияет на содержание азота и калия в иве, что может привести к росту выбросов оксидов азота при сжигании и снижению температуры плавления золы за счет большого количества в ней оксида калия Кㅇ. Из шести изученных генотипов ивы 5 показали высокую температуру плавления золы $\left(>1500{ }^{\circ} \mathrm{C}\right)$ и низкую тенденцию к ошлакованию элементов энергетического оборудования. 
Табл. 1. Топливные характеристики энергетических культур и других биотоплив [1-10]

\begin{tabular}{|c|c|c|c|c|c|}
\hline Показатели & Мискантус & Ива & Тополь & $\begin{array}{c}\text { Солома } \\
\text { зерновых } \\
\text { культур } \\
\text { (для срав- } \\
\text { нения) } \\
\end{array}$ & $\begin{array}{c}\text { Древесная } \\
\text { щепа (для } \\
\text { сравнения) }\end{array}$ \\
\hline Влажность при сборе, \% & $15 \ldots 23$ & $50 \ldots 53$ & $50 \ldots 55$ & $15 \ldots 20$ & 40 \\
\hline $\mathrm{Q}_{\mathrm{H}}^{\mathrm{p}}, \mathrm{MДж/кг} \mathrm{(сух.} \mathrm{мас.)}$ & $17 \ldots 19,5$ & 18,5 & 18,7 & $\sim 18$ & $\sim 19$ \\
\hline Содержание летучих веществ, \% & $>78$ & 79 & 83 & $>70$ & $>70$ \\
\hline Зольность, \% & $2,3 \ldots 3,7$ & $1,5 \ldots 2$ & $0,5 \ldots 1,9$ & $3 \ldots 4$ & $0,6 \ldots 1,5$ \\
\hline \multicolumn{6}{|l|}{ Элементный состав, \%: } \\
\hline $\mathrm{C}$ & 46,97 & 50,28 & 47,95 & $42 \ldots 43$ & 50 \\
\hline $\mathrm{H}$ & 5,57 & 5,98 & 5,92 & 5 & 6 \\
\hline $\mathrm{O}$ & 45,82 & 42,65 & 45,29 & $37 \ldots 38$ & 43 \\
\hline $\mathrm{Cl}$ & 0,04 & $0,02 \ldots 0,03$ & $0,03 \ldots 0,04$ & $0,2 \ldots 0,75$ & 0,02 \\
\hline $\mathrm{K}^{*}$ & $0,46 \%$ & $\begin{array}{c}123,3 \\
\text { г/кг золы }\end{array}$ & 0,21 & $0,2 \ldots 0,98 \%$ & $0,13 \ldots 0,35 \%$ \\
\hline $\mathrm{N}^{*}$ & $0,16 \ldots 0,57$ & $0,4 \ldots 1,0$ & $0,77 \ldots 0,9$ & $0,35 \ldots 0,41$ & 0,3 \\
\hline $\mathrm{S}$ & 0,28 & $0,03 \ldots 0,34$ & $0,03 \ldots 0,2$ & $0,13 \ldots 0,16$ & 0,05 \\
\hline Температура плавления золы, ${ }^{\circ} \mathrm{C}$ & $1250 \ldots 1385$ & $>1500$ & $1200 \ldots 1500$ & $950 \ldots 1000$ & $1000 \ldots 1400$ \\
\hline
\end{tabular}

*Содержание зависит от объема вноса удобрений

Изучение элементного и биохимического состава образцов ивы показало, что генотип с наивысшим содержанием лигнина $(27,1 \%)$ имеет наибольшую зольность $(2,9 . .3,2$ \%). И наоборот, генотип с наименьшим содержанием лигнина $(15,5 \%)$ имеет минимальную зольность $(1,1 \ldots 1,4 \%)$. Наибольшую теплоту сгорания имеют генотипы с высоким содержанием углерода и малым содержанием кислорода. В целом, в работе [1] сделан вывод о хороших топливных характеристиках биомассы ивы (за исключением одного генотипа) и перспективности выращивания и использования этого вида биотоплива.

Авторы [2] исследовали топливные характеристики четырех многолетних травянистых энергетических культур - мискантуса, проса прутьевидного, арундо тростникового, артишока испанского в сравнении с «эталонным» топливом - древесными гранулами австрийского производства. По сравнению с древесиной, исследованные многолетние энергокультуры имеют гораздо большую зольность, из них наименьшая - у мискантуса
(2,3 \% сух. мас.). Повышенная зольность объясняется метаболизмом быстрого роста (накапливание питательных веществ) и отличной от древесины органической структурой ( $\mathrm{SiO}_{2}$-фитолиты). Кроме того, на зольность большое влияние оказывает сезон сбора урожая и применяемая технология сбора. Как правило, основными элементами, формирующими золу, являются (в порядке уменьшения значимости) $\mathrm{Si}, \mathrm{K}, \mathrm{Ca}, \mathrm{Cl}, \mathrm{S}$. У мискантуса по сравнению с другими культурами содержание $\mathrm{Si}, \mathrm{K}, \mathrm{Ca}$ наименьшее.

Кроме того, исследованные энергокультуры (кроме проса прутьевидного) по сравнению с древесными гранулами характеризуются повышенной потенциальной способностью вызывать коррозию элементов энергооборудования, что отражается показателем $\mathrm{Cl} / \mathrm{S}>1$. Формирование свободного газообразного хлора при сульфатации щелочных или тяжелых металлов в отложениях на трубах котла приводит к явлению коррозии. Особенно неблагоприятным является сочетание $\mathrm{Cl} / \mathrm{S}>1$ при высоком содержании Са (как у ар- 
тишока испанского). Для древесных гранул отношение $\mathrm{Cl} / \mathrm{S}<1$. Также энергетические культуры имеют более высокое содержание азота, чем лесная древесина, что приводит к бо́льшим выбросам $\mathrm{NO}_{\mathrm{x}}$ при горении. Наблюдается тенденция к ошлаковыванию элементов оборудования.

Несмотря на недостатки биотоплива из энергетических культур в сравнении с древесными гранулами, в целом они являются неплохим топливом, требующим тщательного подхода к использованию. Во многих случаях эти биотоплива могут удовлетворять существующим нормам по выбросам загрязняющих веществ (если только они не являются необоснованно завышенными). Так, например, из данных таблицы 2 видно, что показатели горения щепы мискантуса полностью находятся в пределах австрийских лимитов для эмиссии твердых частиц, оксидов азота и СО.

Табл. 2. Средние показатели эмиссии при горении биотоплива из энергетических культур, $\mathrm{M \Gamma} / \mathrm{HM}^{3}\left(13 \% \mathrm{O}_{2}\right.$, сух. мас.) [2]

\begin{tabular}{|c|c|c|c|c|c|}
\hline Загрязняющие вещества & $\begin{array}{l}\text { Просо } \\
\text { прутье- } \\
\text { видное }\end{array}$ & $\begin{array}{c}\text { Арундо } \\
\text { тростниковый }\end{array}$ & Мискантус & $\begin{array}{c}\text { Древесные } \\
\text { гранулы } \\
\text { (для срав- } \\
\text { нения) }\end{array}$ & $\begin{array}{c}\text { Австрийские } \\
\text { нормы по выб- } \\
\text { росам для } \\
\text { установок } \\
100 \ldots 350 \text { кВт }\end{array}$ \\
\hline $\begin{array}{l}\text { Твердые частицы, всего, } \\
\text { в т.ч < } 1 \text { нm (аэрозоли) }\end{array}$ & $\begin{array}{l}58 \\
50\end{array}$ & $\begin{array}{c}102 \\
67\end{array}$ & $\begin{array}{l}27 \\
16\end{array}$ & $\begin{array}{l}21 \\
16\end{array}$ & 150 \\
\hline $\mathrm{NO}_{\mathrm{x}}$ & 368 & 363 & 187 & 106 & $350 * / 250 * *$ \\
\hline $\mathrm{HCl}$ & 18 & 67 & 59 & 3 & \\
\hline $\mathrm{SO}_{2}$ & 91 & 278 & 53 & 3 & \\
\hline $\mathrm{CO}$ & 145 & 443 & 55 & 1 & 250 \\
\hline
\end{tabular}

* Для химически необработанных древесных отходов

** Для лесной древесины

Для решения проблемы ошлаковывания поверхностей котла при сжигании энергетических культур авторы [2] предлагают снижать температуру горения путем использования охлаждаемых решеток и стенок топки. Другой подход может заключаться в предварительной обработке биомассы - выщелачивание (для удаления проблематичных химических элементов) или добавлении извести для повышения температуры плавления шлаковых отложений. Еще один возможный метод - совместное сжигание энергокультур с древесиной, в результате чего снизится эмиссия $\mathrm{HCl}, \mathrm{SO}_{2}, \mathrm{NO}_{\mathbf{x}}$ и твердых частиц.

В работе [3] изучены характеристики горения биомассы нескольких энергетических культур, в том числе ивы, тополя, мискантуса. В основном полученные результаты совпадают с выводами приведенных выше исследований. Ива имеет высокую температуру плавления золы $\left(>1500^{\circ} \mathrm{C}\right)$ и наименьшие проблемы с ошлакованием поверхностей энергооборудования. Зольность мисканту- са $(6,7 \%)$ заметно выше зольности ивы $(1,9 \%)$ и тополя $(1,7 \%)$. Это же относится и к содержанию азота. Наихудшие топливные свойства из рассмотренных культур имеет артишок испанский. В отличие от работы [2] авторы [3] считают, что при сжигании энергетических культур (кроме артишока испанского) не будет возникать серьезных проблем с коррозией элементов энергооборудования, поскольку содержание хлора в этих культурах низкое $(<0,1 \%)$.

Выращивание энергетических культур в Украине

На сегодня в Украине есть несколько компаний, занимающихся выращиванием энергетических культур на коммерческом уровне. Еще ряд компаний планируют в ближайшее время выйти на этот рынок. Некоторые из них кратко описаны ниже.

Компания "Salix Energy", основанная в 2010 году, имеет наибольшие в Украине плантации энергетической ивы (Salix Viminalis), располо- 
женные в Волынской и Львовской областях (> 1500 га). Разводятся 6 сортов ивы, в том числе польские, шведские. В 2013 г. компания зарегистрировала свой собственный сорт «Марцияна» (единственный официально зарегистрированный в Украине). На 2014-2015 гг. имеются планы по расширению плантаций ивы до 2,5...3 тыс. га и началу промышленного сбора урожая. "Salix Energy" планирует собирать щепу из энергетической ивы для производства тепловой и электрической энергии на территории Украины [11].

Компания "Phytofuels" выращивает целый ряд энергетических культур (просо прутьевидное, мискантус, ива, сорго сахарное и др.) на площади более 35 тыс. га в Полтавской области. Брикеты и гранулы, произведенные из этих культур, "Phytofuels" поставляет отечественным и зарубежным потребителям. В научных вопросах компания тесно сотрудничает с Институтом биомассы и устойчивого развития (г. Полтава) и Университетом Вагенингена (Нидерланды).

Агрохолдинг KSG Agro, владеющий 65 тыс. га земель в Днепропетровской области, развивает новое направление своего бизнеса выращивание мискантуса. В 2013 году на 33 га агрохолдинга успешно взошли маточные плантации культуры. На 2014 г. запланирована высадка еще 400 га мискантуса, а еще через год общая площадь под эту энергокультуру должна достичь более 2000 га. Биомасса мискантуса будет использоваться для производства твердого биотоплива.

ООО «Аграрное Содружество» в 2011 г. приступило к реализации проекта по выращива-нию энергетической ивы (Salix Viminalis) и производству топливных гранул из нее. Земельный фонд проекта - 2000 га, расчетная производственная мощность завода - 24 тыс. т/год.

В Украине также проводится широкая научно-исследовательская работа, посвященная энергетическим культурам. Большой вклад в это направление вносит Институт биоэнергетических культур и сахарной свеклы Национальной академии аграрных наук Украины. Так, например, в Институте ведется работа по изучению генофонда ивы рода Salix L. различно- го эколого-географического происхождения по характеристикам продуктивности, пригодности к механизированному уходу и сбору, энергетической ценности. На опытном участке Института высажено 11 видов и 3 гибрида Salix L. [12]. Исследуются вопросы урожайности сахарного сорго, мискантуса и других культур. Подготовлен Атлас высокопродуктивных биоэнергетических культур [13].

Несмотря на довольно активное развитие в последние годы выращивания энергетических культур в Украине, существует ряд проблем, требующих разрешения. Одна из них - отсутствие энергокультур в классификаторе сельскохозяйственных культур. На сегодня энергетическая ива включена в классификатор как техническая культура, тогда как мискантуса и других энергокультур там нет вообще. Это может создать юридические и другие проблемы на определенном этапе хозяйственной деятельности производителей этих культур. Кроме того, случается, что производители энергокультур сталкиваются с необходимостью уплаты НДС при оформлении своих отношений с инвестором, тогда как они еще не произвели никакой продукции. Это связано с тем, что продукцией считаются саженцы, выращенные самой компанией для использования на своих же плантациях. Еще одна проблема заключается в том, что производитель энергокультур не считается «сельхозпроизводителем» и не имеет соответствующих льгот (например, по аренде техники), пока он не произвел первую продажу своего урожая. Учитывая, что урожай ивы и тополя собирается каждые 3-4 года, период до первой продажи является достаточно длительным.

Для ускорения развития данного сектора в Украине специалисты Института технической теплофизики НАН Украины считают необходимым внедрить механизмы государственного стимулирования выращивания энергетических культур. Один из предлагаемых механизмов субсидирование энергоплантаций на уровне 10 тыс. грн./га. Другим инструментом может быть частичное покрытие государством процентных ставок коммерческих банков. Рекомендуется предусмотреть соответствующее финансирование из Госбюджета Украины в 
2015-2017 гг.

По оценкам специалистов ИТТФ НАН Украины в стране имеется 3...4 млн. га неиспользуемых сельскохозяйственных земель (по данным 2012 г. - 3,5 млн. га), которые можно задействовать для выращивания энергетических культур. Рекомендуется для этого направления ис-пользовать до 2 млн. га, разделив их (согласно одному из возможных сценариев) между кукурузой на биогаз (1 млн. га), ивой (0,5 млн. га), тополем (0,2 млн. га) и мискантусом (0,3 млн. га). Реализация такого сценария даст возможность

Табл. 3. Концепция ИТТФ НАН Украины для выращивания энергетических культур в Украине

\begin{tabular}{|c|c|c|c|}
\hline Показатели & 2014 г. & 2020 г. & 2030 г. \\
\hline $\begin{array}{l}\text { Площадь под энергетическими культурами } \\
\text { (коммерческие плантации), всего, тыс. га }\end{array}$ & 3 & 200 & 1000 \\
\hline \multicolumn{4}{|l|}{ Структура площзадей по культурам, тыс. га: } \\
\hline - ива & 2 & 50 & 250 \\
\hline - мискантус & $\sim 0$ & 30 & 150 \\
\hline - тополь & $\sim 0$ & 20 & 100 \\
\hline - кукуруза (на биогаз) & 1 & 100 & 500 \\
\hline Урожай энергетических культур (всего), млн. т у.т./год & 0,017 & 1,00 & 4,98 \\
\hline \multicolumn{4}{|l|}{ Структура урожая по культурам, млн. $m$ у.m./год: } \\
\hline - ива & 0,013 & 0,33 & 1,66 \\
\hline - мискантус & $\sim 0$ & 0,19 & 0,94 \\
\hline - тополь & $\sim 0$ & 0,11 & 0,54 \\
\hline - кукуруза (на биогаз) & 0,004 & 0,37 & 1,84 \\
\hline \multicolumn{4}{|l|}{ Показатели, используемье в концеепцции } \\
\hline \multicolumn{4}{|l|}{ Распределение общей площади под энергокультурами, \% } \\
\hline - ива & \multicolumn{3}{|c|}{25} \\
\hline - мискантус & \multicolumn{3}{|c|}{15} \\
\hline - тополь & \multicolumn{3}{|c|}{10} \\
\hline - кукуруза (на биогаз) & \multicolumn{3}{|c|}{50} \\
\hline \multicolumn{4}{|l|}{ Урожайность*, сух. т/га в год: } \\
\hline - ива & \multicolumn{3}{|c|}{12} \\
\hline - мискантус & \multicolumn{3}{|c|}{12} \\
\hline - тополь & \multicolumn{3}{|c|}{9,5} \\
\hline - кукуруза на биогаз (свежая масса) & \multicolumn{3}{|c|}{30} \\
\hline \multicolumn{4}{|l|}{ Теплота сгорания (сухой массы), МДж/кг: } \\
\hline - ива & \multicolumn{3}{|c|}{18} \\
\hline - мискантус & \multicolumn{3}{|c|}{17} \\
\hline - тополь & \multicolumn{3}{|c|}{18,5} \\
\hline - кукуруза на биогаз & \multicolumn{3}{|c|}{$\begin{array}{l}\text { выход } \mathrm{CH}_{4}: 100 \text { м }^{3} / \text { т силоса* } \\
\text { содержание } \mathrm{CH}_{4} \text { в биогазе: } 60 \%\end{array}$} \\
\hline
\end{tabular}

\footnotetext{
* Консервативный подход
} 


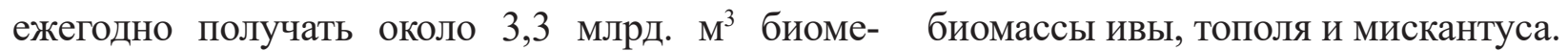
тана из силоса кукурузы и 6,3 млн. т у.т. за счет

Табл. 4. Технико-экономические показатели выращивания энергетического тополя в Украине на плантации с 2-х летним оборотом (расчет на 1 га)

\begin{tabular}{|c|c|c|}
\hline Показатели & $\begin{array}{c}\text { Без } \\
\text { субсидий }\end{array}$ & $\begin{array}{c}\text { С субсидией } \\
620 \text { евро/га на } \\
\text { создание план- } \\
\text { тации } \\
\end{array}$ \\
\hline $\begin{array}{l}\text { Посадка (покупка саженцев - } 6000 \text { шт./га, подготовка почвы), } \\
\text { евро/га }\end{array}$ & 1191 & 571 \\
\hline $\begin{array}{l}\text { Первый цикл плантации (года 1...2): } \\
\text { - уход за плантацией (культивация, боронование, полив), евро/га } \\
\text { - сбор урожая и доставка биомассы потребителю*, евро/га } \\
\text { - урожайность**, т/га } \\
\text { - отпускная цена биомассы, евро/т } \\
\text { - доход от продажи биомассы, евро/га }\end{array}$ & \multicolumn{2}{|c|}{$\begin{array}{c}306 \\
335 \\
40 \\
25(400 \text { грн./т) } \\
994\end{array}$} \\
\hline $\begin{array}{l}\text { Возврат инвестиций после 1-го сбора урожая } \\
\text { (суммарный доход/суммарные затраты) }\end{array}$ & 0,54 & 0,82 \\
\hline $\begin{array}{l}\text { Второй ичикл плантации (года 3...4): } \\
\text { - уход за плантацией (боронование, полив, применение пестицидов), } \\
\text { евро/га } \\
\text { - сбор урожая и доставка биомассы потребителю, евро/га } \\
\text { - урожайность, т/га } \\
\text { - отпускная цена биомассы, евро/т } \\
\text { - доход от продажи биомассы, евро/га }\end{array}$ & \multicolumn{2}{|c|}{$\begin{array}{c}265 \\
353 \\
42 \\
25(400 \text { грн./T) } \\
1049\end{array}$} \\
\hline $\begin{array}{l}\text { Возврат инвестииий после 2-го сбора урожая } \\
\text { (суммарный доход/суммарные затраты) }\end{array}$ & 0,83 & 1,12 \\
\hline $\begin{array}{l}\text { Цикльл 3...7 (года 5...14): } \\
\text { - уход за плантацией, евро/га } \\
\text { - сбор урожая и доставка биомассы потребителю, евро/га } \\
\text { - урожайность, т/га } \\
\text { - отпускная цена биомассы, евро/т } \\
\text { - доход от продажи биомассы, евро/га } \\
\text { - ликвидация плантации, евро/га }\end{array}$ & \multicolumn{2}{|c|}{$\begin{array}{c}1323 \\
1766 \\
42 \\
25(400 \text { грн./T) } \\
5245 \\
100\end{array}$} \\
\hline $\begin{array}{l}\text { Весь период существования плантащии (14 лет): } \\
\text { - средняя урожайность за год, т/га } \\
\text { - суммарные затраты, евро/га } \\
\text { - суммарный доход, евро/га } \\
\text { - общая прибыль (разность дохода и затрат), евро/га } \\
\text { - суммарный доход/суммарные затраты }\end{array}$ & $\begin{array}{c}27 \\
5639 \\
7288 \\
1649 \\
1,29\end{array}$ & $\begin{array}{c}27 \\
5019 \\
7288 \\
2269 \\
1,45\end{array}$ \\
\hline
\end{tabular}

* Здесь и далее в таблице - доставка в радиусе 30 км

** Здесь и далее в таблице - биомасса с влажностью при сборе (W 55 \%) 
C учетом разработанных ИТТФ концепций развития различных секторов биоэнергетики, считаем, что общая площадь для выращивания энергетических культур в Украине может составить около 200 тыс. га в 2020 г. и до 1 млн. га в 2030 г. (табл. 3). Соответственно, урожай этих культур будет эквивалентен 1 млн. т у.т. в 2020 г. и около 5 млн. т у.т. в 2030 г.

Важным вопросом являются экономические показатели выращивания энергокультур, такие как удельные затраты на создание плантации и уход за ней, доход от реализации урожая, период возврата инвестиций и другие. Результаты предварительного технико-экономического обоснования выращивания энергетического тополя с 2-х летним циклом сбора урожая в Украине представлены в таблице 4.

Из данных таблицы видно, что при отпускной цене биомассы 400 грн./т возврат инвестиций (то есть отношение суммарного дохода к суммарным затратам) составляет после 1-го сбора урожая 0,54 , после 2-го сбора урожая - 0,83, за весь срок существования плантации (14 лет, 7 циклов) - 1,29. Это означает, что простой срок окупаемости проекта по выращиванию тополя составляет около 6 лет. При наличии государственной субсидии на создание плантации тополя в размере 10 тыс. грн./га (620 евро/га) возврат инвестиций после 1-го цикла составит $82 \%$, после второго - $112 \%$, за весь срок существования плантации - $145 \%$. То есть в данном случае простой срок окупаемости проекта - до 4 лет. Для окупаемости плантации после 2-го сбора и продажи урожая (т.е. в течение 4-х лет), цена биомассы должна составлять около 480 грн./т при отсутствии субсидий и 360 грн./т при наличии субсидии в 10 тыс. грн./га (620 евро/га).

Оценка необходимой величины субсидий из Госбюджета Украины на выращивание энергокультур выполнена на примере ивы для 2014-2016 гг, исходя из прогнозируемого объема замещения природного газа биомассой при производстве тепловой энергии - 250 млн. м $^{3}$ (2014 г.), 500 млн. м (2015 г.), 1 млрд. м (2016 г.). Результаты показывают, что если энергетические культуры составляют 20 \% всего объема ис- пользуемой биомассы, то общая сумма необходимой субсидии на энергоплантации - 84...338 млн. грн./год (табл. 5). При этом доля субсидии от стоимости природного газа, замещаемого энергокультурами, составляет 38 \%.

\section{Выводы}

Несмотря на ряд недостатков биотоплива из энергетических культур в сравнении с древесными гранулами, в целом энергокультуры являются неплохим топливом, требующим тщательного подхода к использованию. Во многих случаях эти биотоплива могут удовлетворять существующим нормам по выбросам загрязняющих веществ (если только они не являются необоснованно завышенными).

На сегодня в Украине есть несколько компаний, занимающихся выращиванием энергетических культур на коммерческом уровне. Еще ряд компаний планируют в ближайшее время выйти на этот рынок. Для ускорения развития данного сектора в Украине специалисты ИТТФ НАН Украины считают необходимым внедрить механизмы государственного стимулирования выращивания энергетических культур. Один из предлагаемых механизмов - субсидирование энергоплантаций на уровне 10 тыс. грн./ га. Другим инструментом может быть частичное покрытие государством процентных ставок коммерческих банков. Рекомендуется предусмотреть соответствующее финансирование из Госбюджета Украины в 2015-2017 гг.

По оценкам ИТТФ, в Украине имеется 3 ...4 млн. га неиспользуемых сельскохозяйственных земель, которые можно задействовать для выращивания энергетических культур. Рекомендуется для этого направления использовать до 2 млн. га, разделив их (согласно одному из возможных сценариев) между кукурузой на биогаз (1 млн. га), ивой (0,5 млн. га), тополем (0,2 млн. га) и мискантусом (0,3 млн. га). Реализация такого сценария даст возможность ежегодно получать около 3,3 млрд. $\mathrm{M}^{3}$ биометана из силоса кукурузы и 6,3 млн. т у.т. за счет биомассы ивы, тополя и мискантуса.

Согласно концепции ИТТФ, общая площадь для выращивания энергетических культур в Украине может составить около 200 тыс. га 
в 2020 г. и до 1 млн. га в 2030 г. Соответственно, урожай этих культур будет эквивалентен 1 млн. т у.т. в 2020 г. и около 5 млн. т У.т. в 2030 г.

Оценка необходимой величины субсидий из Госбюджета Украины на выращивание энергокультур выполнена на примере ивы для 2014-2016 гг., исходя из прогнозируемого объема замещения природного газа биомассой при производстве тепловой энергии -
250 млн. м $^{3}$ (2014 г.), 500 млн. м $^{3}$ (2015 г.), 1 млрд. $\mathrm{M}^{3}$ (2016 г.). Результаты показывают, что если энергетические культуры составляют $20 \%$ всего объема используемой биомассы, то общая сумма необходимой субсидии на энергоплантации $-84 \ldots 338$ млн. грн./год. При этом доля субсидии от стоимости природного газа, замещаемого энергокультурами, составляет $38 \%$.

Табл. 5. Расчет необходимой субсидии из Госбюджета Украины на выращивание энергетических культур (на примере ивы)

\begin{tabular}{|c|c|c|c|}
\hline Показатели & 2014 г. & 2015 г. & 2016 г. \\
\hline $\begin{array}{l}\text { Прогнозируемый объем замещения природного газа } \\
\text { биотопливом, млн. } \text { м }^{3}\end{array}$ & 250 & 500 & 1000 \\
\hline Калорийность биотоплива (щепа) (при W 40 \%), МДж/кг & 10 & 10 & 10 \\
\hline Период эксплуатации котельной, суток & 185 & 185 & 185 \\
\hline Потребность в биотопливе (при W 40 \%), тыс. т & 844 & 1688 & 3375 \\
\hline $\begin{array}{l}\text { Доля энергокультур (ива) в общем объеме используемого } \\
\text { биотоплива, \% }\end{array}$ & 20 & 20 & 20 \\
\hline Урожайность ивы (влажная масса), т/га/год & 20 & 20 & 20 \\
\hline Необходимая площадь плантации ивы, тыс. га & 8,4 & 16,9 & 33,8 \\
\hline $\begin{array}{l}\text { Необходимая дотация из Госбюджета Украины на создание } \\
\text { энергоплантаций, } \\
\text { тыс. грн./га } \\
\text { млн. грн. }\end{array}$ & $\begin{array}{c}10 \\
84,4\end{array}$ & $\begin{array}{c}10 \\
168,8\end{array}$ & $\begin{array}{c}10 \\
337,5\end{array}$ \\
\hline $\begin{array}{l}\text { Стоимость замещаемого энергетической ивой природного газа } \\
\left.\text { (при цене } 380 \$ / 1000 \mathrm{M}^{3}\right) \text {, млн. грн. }\end{array}$ & 225 & 450 & 900 \\
\hline $\begin{array}{l}\text { Доля необходимой субсидии на энергокультуры от } \\
\text { стоимости природного газа, замещаемого ивой }\end{array}$ & $38 \%$ & $38 \%$ & $38 \%$ \\
\hline
\end{tabular}

$\mathrm{W}$ - влажность (по массе)

\section{ЛИТЕРАТУРА}

1. B.A. Gudka. Combustion characteristics of some imported feedstocks and short rotation coppice (SRC) willow for UK power stations, 2012 http://etheses.whiterose.ac.uk/3352/1/Combustion Characteristics_of_some_Imported_Feedstocks_ and SRC willow_for_UK power_stations.pdf

2. J. Dahl, I. Obernberger. Evaluation of the combustion characteristics of four perennial energy crops (Arundo Donax, Cynara Cardunculus, Miscanthus x Giganteus and Panicum Virgatum). Proc. of 2nd World Conference on Biomass for Energy, Industry and Climate Protection, 10-14 May
2004, Rome, Italy, P. 1265 - 1270

3. E. Karampinis, D. Vamvuka, S. Sfakiotakis et al. Comparative Study of Combustion Properties of Five Energy Crops and Greek Lignite // Energy \& Fuels, 2012, N 26(2), P. $869-878$.

h t t p : / / w w w. re s e a r c h g a t e.ne t / publication/224437353_A_Comparative_Study_of_ Combustion_Properties_of_Five_Energy_Crops_and_Greek_Lignite

4. Energy from field energy crops - a handbook for energy producers. AEBIOM, 2009

http://www.aebiom.org/wp-content/uploads/file/ Publications/Handbook\%20for\%20energy $\% 20$ 
producers.pdf

5. L. Nikolaisen, C. Nielsen, M.G. Larsen et al. Straw for energy production. Technology Environment - Economy. The Centre for Biomass Technology, Denmark. 1998.

6. K. Suadicani, A. Evald, H. H. Jakobsen. Wood chips for energy production. Technology Environment - Econo-my. The Centre for Biomass Technology, Denmark. 1993.

7. Блюм Я.Б., Гелетуха Г.Г., Григорюк И.П. и $\partial p$. Новейшие технологии биоэнергоконверсии. К: «Аграр Ме-диа Груп», 2010. - 326 с.

8. New dedicated energy crops for solid biofuels. AEBIOM, FP6 RESTMAC project, 2008 http://www.aebiom.org/IMG/pdf/Dedicated energy_crops_for_solid_biofuels_2008_January.pd $\bar{f}$

9. $M$. Wachendorf. Thermal use of agricultural biomass. BOVA course "Energy Crops and Biogas Production, 3-7 March 2008, Tartu, Estonia http://www.bioenergybaltic.ee/bw_client_files/ bioenergybaltic/public/img/File/BOVĀ/
Wachendorf thermal use of agricultural biomass. pdf

10. T. van der Sluis, R. Poppens, P. Kraisvitnii et al. Reed harvesting from wetlands for bioenergy. Alterra report 2460, 2013

http://www.switchgrass.nl/upload mm/ a/5/9/99e205b9-c2ea-4274-a1f8-8e94047094e0

Reed $\% 20$ report $\% 20$ Pellets $\% 20$ for $\% 20$ Power $\% 2 \overline{0}$ 2460\%20October\%202013.pdf

11. Гнап И.В. Выращивание энергетической вербы на Волыни: результаты за первые 3 года. Презентация на семинаре "GREENEXPO. Альтернативная энергетика», 18 октября 2013 г., Киев.

12. Рӧ̈к М.В., Гументик М.Я., Мамайсур B.B. Перспективи вирощування енергетичної верби для виробництва твердого біопалива // Біоенергетика, № 2, 2013, С. 18 - 19.

13. Гументик М.Я. Атлас високопродуктивних біоенергетичних культур // Біоенергетика, № 2, 2013, C. $6-7$. 


\section{PROSPECTS FOR GROWING AND USE OF ENERGY CROPS IN UKRAINE. PART 2}

\section{Geletukha G.G., Zheliezna T.A., Tryboi O.V.}

Institute of Engineering Thermophysics of the National Academy of Sciences of Ukraine, vul. Zhelyabova, 2a, Kyiv, 03680, Ukraine

Fuel properties of energy crops are considered in the paper. Disadvantages of energy crops as a fuel are analyzed and possible ways for mitigation of their negative influence are suggested. It is shown that despite some disadvantages of energy crops as compared to wood pellets, on the whole they are a good fuel, which requires well thought-out approach to its use. In many cases the biofuels can meet existing emission limits (unless they are unduly strict). The paper also covers state of the art and prospects for the development of the sector in Ukraine. A conception for growing energy crops in the country is suggested. To push development of the sector in the Ukraine the authors consider it necessary to introduce state support for growing energy crops. One of the possible mechanisms is a subsidy for creation of energy crop plantation; another instrument may be partial covering commercial rate interest by the state. References 13, table 5 .

Key words: energy crops, energy plantations, biomass, biofuels, bioenergy.

1. B.A. Gudka. Combustion characteristics of some imported feedstocks and short rotation coppice (SRC) willow for UK power stations, 2012

http://etheses.whiterose.ac.uk/3352/1/Combustion Characteristics_of_some_Imported_Feedstocks_and SRC willow for $\overline{\text { UK }}$ power stations.pdf

2. J. Dahl, I. Obernberger. Evaluation of the combustion characteristics of four perennial energy crops (Arundo Donax, Cynara Cardunculus, Miscanthus x Giganteus and Panicum Virgatum). Proc. of 2nd World Conference on Biomass for Energy, Industry and Climate Protection, 10-14 May 2004, Rome, Italy, p. 1265-1270

3. E. Karampinis, D. Vamvuka, S. Sfakiotakis et al. Comparative Study of Combustion Properties of Five Energy Crops and Greek Lignite // Energy \& Fuels, 2012, N 26(2), p. 869-878. http://www.researchgate.net/publication/224437353 A Comparative_Study_of_Combustion_Properties_of_Five_ Energy_Crops_and_Greek_Lignite

4. Energy from field energy crops - a handbook for energy producers. AEBIOM, 2009

http://www.aebiom.org/wp-content/uploads/file/ Publications/Handbook\%20for\%20energy\%20producers. pdf

5. L. Nikolaisen, C. Nielsen, M.G. Larsen et al. Straw for energy production. Technology - Environment Economy. The Centre for Biomass Technology, Denmark. 1998.

6. K. Suadicani, A. Evald, H. H. Jakobsen. Wood chips for energy production. Technology - Environment Econo-my. The Centre for Biomass Technology, Denmark. 1993.

7. Blium Ya.B., Geletukha G.G., Grygoriuk I.P. et al. Modern technologies for bioenergy conversion. $-\mathrm{K}$ : "Agrar Me-dia Group", 2010. - 326 p. (Ukr.)

8. New dedicated energy crops for solid biofuels. AEBIOM, FP6 RESTMAC project, 2008 http://www.aebiom.org/IMG/pdf/Dedicated_energy_ crops_for_solid biofuels_2008_January.pdf

9. $\bar{M}$. Wachendorf. Thermal use of agricultural biomass. BOVA course "Energy Crops and Biogas Production, 3-7 March 2008, Tartu, Estonia http://www.bioenergybaltic.ee/bw client files/ bioenergybaltic/public/img/File/BOVĀ/Wachendorf thermal use of agricultural biomass.pdf

10. T. van $\bar{d}$ er Shis, R. Poppens, P. Kraisvitnii et al. Reed harvesting from wetlands for bioenergy. Alterra report 2460, 2013

http://www.switchgrass.nl/upload_mm/a/5/9/99e205b9c2ea-4274-a1f8-8e94047094e0_Reed\%20report\%20 Pellets\%20for\%20Power\%202460\%20October\%202013. pdf

11. Gnap I.V. Growing willow for energy at Volyn: results of the first 3 years. Presentation at the seminar "GREENEXPO. Alternative energy", 18 October 2013, Kyiv. (Ukr.)

12.RoikM.V., GumentilM.Ya., Mamaysur V.V.Prospects for the cultivation of energy willow for solid biofuel production // Bioenergy, № 2, 2013, p. 18-19. (Ukr.)

13. GumentikM.Ya. Atlas of the high-productive energy crops // Bioenergy, № 2, 2013, p. 6-7. (Ukr.)

Получено 24.10.2014 Received 24.10.2014 